(1) CrossMark

Cite this: Anal. Methods, 2016, 8, 2539

DOI: 10.1039/c6ay90031c

www.rsc.org/methods

\title{
Correction: Meat and poultry nitrogen factors
}

\author{
Analytical Methods Committee, AMCTB No 63
}

Correction for 'Meat and poultry nitrogen factors', Analytical Methods Committee AMCTB No 63, Anal. Methods, 2014, 6, 4493-4495.

Several details within this technical brief are updated to reflect important new information regarding these nitrogen factors. The details of the required amendments are as follows.

In the section 'Nitrogen factors for meat and poultry', the complete text of the sub-section 'Pork' is amended as follows:

There was an extensive study of pork nitrogen factors, which was published in $1991 .^{\mathbf{1 0}}$ However, the genetics, breeds and methods of rearing pigs have changed significantly over the last 21 years, also the carcase weights at slaughter have increased. In addition to home production, a substantial amount of pork is imported to the UK from Europe especially Denmark and the Netherlands. Most of the imported pork goes into pork products or is imported as cured pork (ham or bacon). Therefore, a new study was commissioned and published in $2015^{\mathbf{1 1}}$ which determined nitrogen factors for the whole side, four main joints of pork (belly, loin, shoulder and leg), and individual shoulder (hand and collar) and leg joints (silverside, topside, shin, chump and flank) from pigs reared in the UK, Denmark and the Netherlands, and compared them to the values of nitrogen factors, where relevant, in the 1991 study. Table 1 gives the recommended nitrogen factors as a result of this new study. The average weight of carcases (84 kg) used in the study was much heavier than the average national UK carcase weight in the 1991 study (70 kg). The UK and Danish median carcase weight was $81 \mathrm{~kg}$, whereas the median Dutch carcase weight was $89 \mathrm{~kg}$. The overall \% lean of the carcases was $61 \%$, which is the highest category in the EU classification scheme. The recommended factor for the whole side has changed from 3.50 in the 1991 study to 3.60 .

In the section 'Nitrogen factors for meat and poultry', the final sentence of the sub-section 'Chicken' is amended as follows:

A factor of 3.75 (reduced from 3.85) was found,$^{16}$ and meat from spent hens is no longer being used in poultry products.

Table 1 is amended as follows:

Table 1 Recommended nitrogen factors for pork $^{a}$

\begin{tabular}{|c|c|c|c|c|c|c|}
\hline \multirow[b]{2}{*}{ Joint } & \multirow[b]{2}{*}{ Cut } & \multicolumn{5}{|c|}{ Country } \\
\hline & & DK & NL & UK & All 3 countries & 1991 study for $70 \mathrm{~kg}$ carcase \\
\hline Belly & - & 3.50 & 3.60 & 3.60 & 3.55 & 3.50 \\
\hline Loin & - & 3.65 & 3.75 & 3.70 & 3.70 & 3.65 \\
\hline Shoulder & - & 3.45 & 3.45 & 3.50 & 3.45 & - \\
\hline Shoulder & Collar & 3.40 & 3.55 & 3.50 & 3.45 & 3.40 \\
\hline Shoulder & Hand & 3.50 & 3.40 & 3.55 & 3.50 & 3.45 \\
\hline Leg & - & 3.55 & 3.60 & 3.65 & 3.60 & 3.50 \\
\hline Leg & Chump & 3.65 & 3.75 & 3.70 & 3.70 & - \\
\hline Leg & Flank & 3.45 & 3.50 & 3.50 & 3.50 & - \\
\hline Leg & Shin & 3.50 & 3.45 & 3.60 & 3.50 & - \\
\hline Leg & Silverside & 3.55 & 3.65 & 3.65 & 3.60 & - \\
\hline Leg & Topside & 3.60 & 3.70 & 3.70 & 3.65 & - \\
\hline Whole side & - & 3.55 & 3.60 & 3.60 & 3.60 & 3.50 \\
\hline
\end{tabular}

${ }^{a}$ Values are $\mathrm{g}$ per $100 \mathrm{~g}$ and rounded to nearest 0.05 . 
A new reference (ref. 11) is added to the reference list. This is cited within the amended text of the sub-section 'Pork'. The subsequent references are now cited as follows:

Ref. 12 is cited against the sub-section 'Beef';

Ref. 13 and 14 are cited against the sub-section 'Sheepmeat (Mutton and Lamb)';

Ref. 15 and 16 are cited against the sub-section 'Chicken'; ref. 16 is additionally cited in the amended sentence within this subsection as detailed above;

Ref. 17 is cited against the sub-section 'Turkey'.

The amended reference list follows below.

The Royal Society of Chemistry apologises for these errors and any consequent inconvenience to authors and readers.

\section{References}

10 AMC, Nitrogen Factors for Pork: A Reassessment, Analyst, 1991, 116, 761-766.

11 AMC, A Reassessment of Nitrogen Factors for Pork, Anal. Methods, 2015, 7, 8997-9004.

12 AMC, Nitrogen Factors for Beef: A Reassessment, Analyst, 1993, 118, 1217-1226.

13 AMC, Nitrogen Factors for Sheep Meat. Part 1, Mutton, Analyst, 1995, 120, 1823-1824.

14 AMC, Nitrogen Factors for Sheep Meat. Part 2, Lamb Meat, Analyst, 1996, 121, 889-896. Amendment see, Analyst, 2000, 125, 227, “on p. 895, Table 10, the value for the SE of forequarter fat-free nitrogen should be 0.020 not 0.220 as printed".

15 AMC, Nitrogen Factors for Chicken Meat, Analyst, 2000, 125, 1359-1366.

16 AMC, Revisiting the Nitrogen Factor for Skinless Chicken Breast, Anal. Methods, 2014, 6, 1998-2002.

17 AMC, Nitrogen Factors for Turkey Meat, Analyst, 2002, 127, 859-869. 